\title{
Study of Industrial Cluster and Competitiveness Promotion of Cultural
}

\section{Industry}

\author{
Meng Su ${ }^{1}$
}

${ }^{1}$ Oxbridge College, Kunming University of Science and Technology, Kunming, Yunnan 650106

KEYWORDS: Industry Cluster; Cultural Industry; Competitiveness Promotion

\begin{abstract}
With the development of economic globalization, production and circulation of cultural goods and services are becoming increasingly international and the cultural industry has become an important part of the global economic and social development. From the point of view of the overall situation of international competition, continuously upgrade the competitiveness of cultural industries to cultivate "soft power" of countries and regions, and thus enhance the competitiveness of countries and regions, it has become an important strategy for the world to enhance their international competitiveness. This article explores the concept of competitiveness of cultural industries, content and theoretical sources, and East China provinces and one city in the cultural industry as an example, analyzed the current situation and development trend of China's cultural industry competitiveness, and proposed cultural industry competitiveness strategy.
\end{abstract}

\section{Introduction}

Cultural connotation of industrial clusters. According to Michael Porter ((Porter, 1998) view, industrial clusters (Cluster Industries) is in a particular area, a group of geographically proximate, there is interaction related enterprises and related legal institutions, and commonality with each other and complementary coupling phase. the basic characteristics of industrial clusters include industry spatial concentration of industrial relevance and industrial embeddedness cultural industry cluster is in the field of cultural industries (usually in the media industry as the core), the number of independent and cultural enterprises and related supporting mechanism interrelated, according to the specialization and collaboration established, industrial organization and in certain regional agglomeration and the formation of cultural industry clusters in the general sense to include all the upstream and downstream industry chain of cultural enterprise, which contains five main cultural industries) creative body, making the body, the body spread, and extend the service principal body. According to the strength of the cultural industries and creative attributes, combined with the above definition of cultural industries and cultural industrial cluster architecture and body constitution can be divided into: the core of the cultural industry clusters, industry clusters and the peripheral edge of cultural industries and other groups.. Cultural Industry Competitiveness is a country (region) of cultural industries for the country (region) cultural resources endowment structure (comparative advantage) and the reaction and the ability to adjust the market environment, is a country (region) Cultural Industry Comparative Advantage and Competitive Advantage total, including four core competencies: the overall innovation, market expansion, cost control and sustainable development.

\section{Culture Industry Cluster}


According to theoretical models diamond Porter about industrial competitiveness, the impact of cultural industry cluster competitive advantage factor conditions is the production elements of the system, the demand for health system, cultural system, corporate strategy, related auxiliary industries and government systems behavior system.

The factors of production systems. According to Michael Porter's classification, factors of production can be divided into basic elements and advanced features. The former includes natural resources, geographical conditions, climatic conditions, the junior workers, etc.; the latter including high-tech talent and creativity, leading scientific institutions and disciplines, modern communications networks. There are other features in accordance with the cultural industry with other industries, the cultural industry of production factors including: cultural resources, human resources, capital resources and infrastructure.

Demand system. Mainly refers to public demand for cultural goods and services, which provides development of cultural enterprises, continued investment and drive innovation. Effective demand can continue to stimulate the effective supply of cultural goods and services, thus contributing to the continuous optimization of cultural industries and cultural industries cluster structure. Improve the maturity of the consumer culture, foster cultural need of the discerning type is an important condition to enhance the competitiveness of cultural industries.

The relevant supporting industries system refers to the cultural industries in all aspects of production, distribution, consumption and other support related industries. Because of the cultural industry clusters are usually formed from the upstream to downstream industries has been a series of industry value chain, and industry related degree than the larger, cultural industries Competitive Advantage can not be separated a strong support group of related industries, only with a strong group of related supporting industries can really play to the overall competitive advantage of the cultural industry clusters, such as: information, networking, education, finance and other industries are the foundation upon which the development of the cultural industry clusters. Related and supporting the development of local industry, industrial clusters to enhance industrial competitiveness and cultural prerequisites.

\section{Factors Affecting Cultural Industry Competitiveness}

Cultural resources is the basis for development of cultural industries, industrial development is the expansion of cultural resources. In the process of development of cultural industries, and which side the lead in the evolved cultural resources industry resources, in the development of cultural industries which party ranks to occupy the initiative, to take the initiative. But whether it is relatively static as cultural heritage Historic and cultural resources, or significant penetration of smart present and future cultural resources of knowledge and technology may be crystalline, we have emphasized the importance of knowledge, as well as human resources and financial capital elements investment. In a variety of resources to a large extent, people of knowledge, science and technology endowment carrier, hoping cultural province, to enhance the competitiveness of cultural industries is the key to whether the use of human resources when.

Cultural products, although low-loss high-value-added products, but it is also accompanied by an unstable market risks, including market supply and demand market. Maturity of a country or regional market development often represents a degree of satisfaction and achieves a cultural product market value. Cultural products from the nature point of view, it is a higher level of spiritual needs, to a certain extent, it belongs to human needs Maslow's theory of self-actualization needs, complex. Innovation Ability of Regional Cultural Industry to enhance the competitiveness of local cultural industries have a great role in promoting creative cultural products on the market 
supply will nurture and stimulate consumer demand for cultural products, on the contrary, if the cultural goods market has not yet emerged, for unknown cultural products lurking higher market risk. Thus, on the market of cultural products, especially the needs of the market changes need to be very concerned about the strength of the cultural industry competitiveness through market also needs to practice and test.

Culture and ideology of the culture industry determines the specificity of the cultural industry and the general organization of industrial organization, it also bears a special social responsibility and social functions. Cultural Industry Organization SCP analysis system showed that the cultural industry market structure determines the cultural market behavior of enterprises, and co-influence and restrict market performance culture industry presents different resource allocation status, and ultimately guide the development and competitiveness of the entire cultural industry of implementation, at the same time, the status and trends of cultural industry market performance, which in turn affect the future market structure and market behavior. Thus a key factor, effective cultural industry market structure is to enhance the competitiveness of the region's cultural industries - proved that the cultural industry clusters to bring economies of scale to effectively optimize and enhance the cultural industrial structure, enhance the cultural industry, organizational efficiency and competitiveness .

21st century discovery, culture and communication are inseparable. Especially in the 20th century, with the development of electronic technology, telephone, telegraph, radio, video recording, computer, film, television successive universalization with unprecedented speed and scale of the field of cultural infiltration, copy, production methods and new culture cultural way, gave birth to the culture industry, it is no accident that the cultural industry in the event of this period is the material conditions are met and mature product. Since the mid-20th century, modern science and technology revolution in science and technology to lead the masses into the "information age" in the information technology market and the economic globalization today, the continued integration technology Industry Groups to promote the production and consumption of cultural products. The cultural industry is an inevitable outcome of modern technology, modern science and technology will also lead the world cultural trends in competitive terms.

\section{Cultural Industry Competitiveness Strategy Analysis}

Various regions of China's cultural industry development planning ideas single, similar industrial structure, regional characteristics unclear problem has become a bottleneck in cultural industries for sustainable development \& For example, the cultural industry by many local governments as a breakthrough in development of cultural industries, but between the cultural industry homogenization of serious competition, and in some places even under the banner of cultural industrial park, big enclosure secretly engaged in real estate development \& this blindly follow the trend, mutual competition and duplication, and to bring the waste of resources, serious impact on the development of regional cultural industries quality \& cultural industries face uneven regional development, researchers recommend the development model of the eastern region of cultural industry should be actively followed suit \& Midwest However, our cultural resources in regions different endowments, cultural, geographical, economic and other series differences in factors determine the development of the cultural industry can not be fixed with a simple imitation or consistent pattern of differences between the current \& regional cultural industry competitiveness, does not mean that the development potential of the cultural industry and the future development of the results of the cultural industry. 
Local governments in the development boom in cultural industries, the development of cultural industries to act as advocates, policy makers, industry, investors, project organizers and managers, but because of the strengthening of the role of government functions to highlight the growing problems caused by \& excessive industrial policy easing led to excessive dependence on government business and thus the competitiveness of industry \& lack of government financial support for cultural industry policies to induce businesses to the government as part of culture! customers "to carry out bad game, does not regulate investment behavior and investment impulse greatly reducing the effectiveness of financial resources industry \& facts prove: not in accordance with the production, distribution, sale and consumption of such a cycle to produce the product, do not be industry; rely on government finances continue to inject such an external force money to maintain production continuous chain, can not be regarded as an industry.

Cultural industry chain is one of many separate but interrelated cultural enterprises and related institutions, according to the vertical specialization and collaboration forged linkage, about convergence, one input, complete and efficient forms of industrial organization several US economic output \& Herman believes that there are modern sectors of the economy forward, backward linkages, such linkages are formed by a series of uneven chain process, there is interaction between the various industry sectors, economic development is a another sector accompanied by a series of uneven development department of process \& $\$$ culture industry is the use of creative elements of the abstract cultural converted into both physical and cultural achievements of economic value, and the results of large-scale industrialization and the value derived from the pursuit of new industries \& think any industry body independent architecture complete industrial chain development model is not an easy task \& in addition, the potential risks of industrial operations also need to calm face in the initial stage of cultural \& creative industries, through the industrial chain, rich product content and form effectively lead and meet market demand, thereby enhancing the industry was undoubtedly a wise move.

\section{Conclusion}

In this paper, the theory of cultural industry and competitiveness are reviewed and discussed in the basic sort of cultural industry competitiveness concept, connotation and theoretical sources on the basis of the theory of China's cultural industry competitiveness has been fully grasp the point, and explains analysis of the factors affecting the competitiveness of cultural industries and the internal dynamic mechanism. Drawing an international competitiveness index system and method attempts to propose a new strategy to enhance the competitiveness of cultural industries.

\section{Reference:}

[1] Bassett Urban Culture Strategies and Urban Regeneration: A Case Study and Critique [J] .Environment and Planning, 1993:. 50-66.

[2] David Throsby, The concentric circles model of the cultural industries [J]. Cultural trends.. , 2008 (3), 147-154.

[3] G- Tomas M. Hult Cultural Competitiveness in Global Sourcing [J]. Industrial Marketing Management, 2002 (31).

[4] Yi Fen Huang. A multiple criteria evaluation of creative industries for flie cultural creativity centre in Taiwan [J]. International Journal of Entrepreneurial Behaviour \& Research, 2009 (5). 